\title{
Estudo da remoção e controle de ferro nas águas da nascente Serra do Andrade-MG
}

\author{
Study of the removal and control of iron in the waters of the spring Serra do Andrade-MG \\ Estudio de la remoción y control de hierro em lãs água Del manatial Serra do Andrade-MG
}

\author{
Ipojucan dos Santos Soares \\ ORCID: https://orcid.org/-0000-0001- 6183-4816 \\ Universidade do Estado de Minas Gerais, Brasil \\ E-mail: ipojucam@hotmail.com \\ Matheus Soares Bicalho Costa \\ ORCID: https://orcid.org/0000-0003-1721-2272 \\ Universidade do Estado de Minas Gerais, Brasil \\ E-mail: mateus42b@gmail.com \\ Marcos Antonio Gomes \\ ORCID: https://orcid.org/0000-0002-7696-9307 \\ Universidade Federal de Viçosa, Brasil \\ E-mail: marcosgomesfaenge@gmail.com \\ Aurilaine Ávila de Freitas \\ ORCID: https://orcid.org/0000-0003-1882-473X \\ Universidade do Estado de Minas Gerais, Brasil \\ E-mail: aurilainefreitas@yahoo.com.br \\ Adriano José de Barros \\ ORCID: https://orcid.org/0000-0003-4199-4999 \\ Pontifícia Universidade Católica de Minas Gerais, Brasil \\ E-mail: adrianojosebarros@yahoo.com.br
}

\begin{abstract}
Resumo
Uma das necessidades básicas para a sobrevivência do ser humano é o consumo de água potável, uma vez que além de ser usada para beber também é indispensável na preparação de alimentos e em processos de higiene e limpeza. Por isso, é necessário que a água esteja dentro dos padrões de potabilidade exigidos pelo Ministério da Saúde (MS), que atribuiu à Portaria 518, de 25 de março de 2004, o controle e a vigilância da qualidade da água. O presente estudo teve como objetivo principal propor um processo alternativo para a remoção do ferro (Fe) nas águas da nascente Serra do Andrade - Minas Gerais, por meio de filtração adsortiva com a aplicação do material adsorvente (zeólita). Como referencial teórico, foi estabelecido um diálogo entre os autores que trouxeram uma carga de informações importantes para esta área de pesquisa, tais como Simão et. al (2020), Vistuba_(2010), Carmo (2013), e Cali e Costa (2020). Os procedimentos metodológicos escolhidos para possibilitar o estudo foram, primeiramente, análise documental para coleta de dados, prática para a coleta de amostras da água na primeira e segunda fase do estudo e uma análise final da pesquisa. Foi realizado um estudo prático sobre o uso da zeólita na tentativa de remover íons de ferro na forma de precipitados. Como resultados obtidos, foi possível perceber a importância de novas fontes alternativas de remoção e controle do ferro em águas principalmente naturais e ainda, pode-se dizer que o material adsorvente estudado, zeólita, mostrou-se muito eficiente na remoção do Fe.
\end{abstract}

Palavras-chave: Água; Zeólita; Ferro; Remoção.

\begin{abstract}
One of the basic needs for human survival is the consumption of drinking water, since in addition to being used for drinking it is also indispensable in food preparation and in hygiene and cleaning processes. Therefore, it is necessary for the water to be within the potability standards required by the Ministry of Health (MS), which assigned to Portaria 518, of March 25, 2004, the control and surveillance of water quality. The present study had as main objective to propose an alternative process for the removal of iron $(\mathrm{Fe})$ in the waters of the Serra do Andrade spring - Minas Gerais, by means of adsorptive filtration with the application of the adsorbent material (zeolite). As a theoretical framework, a dialogue was established between the authors who brought a load of important information to this area of research, such as Simão et. al (2020), Vistuba (2010), Carmo (2013), and Cali and Costa (2020). The methodological procedures chosen to make the study possible were, first, document analysis for data collection, practice for collecting water samples in the first and second phase of the study and a final analysis of the research. A practical study was carried out on the use of zeolite in an attempt to remove iron ions in the form of precipitates. As results obtained, it was possible to perceive the importance of new alternative sources of iron removal and control in mainly natural waters and it can also be said that the studied adsorbent material, zeolite, proved to be very efficient in removing Fe.
\end{abstract}

Keywords: Water; Zeolite; Iron; Removal. 


\section{Resumen}

Una de las necesidades básicas para la supervivencia humana es el consumo de agua potable, ya que además de ser utilizada para beber también es indispensable en la preparación de alimentos y en los procesos de higiene y limpieza. Por tanto, es necesario que el agua esté dentro de los estándares de potabilidad exigidos por el Ministerio de Salud (MS), que asignó a Portaria 518, de 25 de marzo de 2004, el control y vigilancia de la calidad del agua. El presente estudio tuvo como objetivo principal proponer un proceso alternativo para la remoción de hierro $(\mathrm{Fe})$ en las aguas del manantial Serra do Andrade - Minas Gerais, mediante filtración adsortiva con la aplicación del material adsorbente (zeolita). Como marco teórico, se estableció un diálogo entre los autores que aportaron una carga de información importante a esta área de investigación, como Simão et. al (2020), Vistuba (2010), Carmo (2013) y Cali y Costa (2020). Los procedimientos metodológicos elegidos para hacer posible el estudio fueron, en primer lugar, el análisis documental para la recogida de datos, la práctica de recogida de muestras de agua en la primera y segunda fase del estudio y un análisis final de la investigación. Se realizó un estudio práctico sobre el uso de zeolita en un intento por eliminar los iones de hierro en forma de precipitados. Como resultados obtenidos, se pudo percibir la importancia de nuevas fuentes alternativas de remoción y control de hierro en aguas principalmente naturales y también se puede decir que el material adsorbente estudiado, la zeolita, demostró ser muy eficiente en la remoción de Fe.

Palabras clave: Agua; Zeolita; Hierro; Eliminación.

\section{Introdução}

A água é um elemento vital no que se refere a seu uso pelo homem e, segundo Simão et al (2020), a água potável e saneamento seguros são reconhecidos como direitos básicos. Apesar disso, a água destinada para consumo humano tem sido frequentemente reconhecida como veículo de transmissão de inúmeras doenças. Como diversas epidemias tiveram sua origem comprovada na distribuição e abastecimento de água, faz-se necessário o devido tratamento para que ela atinja os padrões de portabilidade exigidos para o consumo humano. O presente artigo tem como escopo a análise da remoção e controle de ferro nas águas da nascente Serra do Andrade - Minas Gerais.

O ferro é o metal mais abundante na crosta terrestre e é essencial para a nutrição humana. Pode ser encontrado em solos e em minerais, principalmente como óxido férrico insolúvel. Tal observação é de extrema relevância, pois, quando em excesso, o ferro acarreta problemas de caráter operacional e econômico, como danos causados às tubulações que transportam a água. Segundo relatório da Organização Mundial da Saúde (2011), apesar das concentrações usualmente encontradas não conferirem risco à saúde humana, a presença de ferro e manganês acima do estabelecido pela Portaria $\mathrm{n}^{\circ} 2.914$ do Ministério da Saúde em águas de abastecimento pode trazer coloração de cor ferruginosa, odor e gosto forte, além de causar incrustações nas tubulações, nas bombas, trazendo prejuízo financeiro e à saúde dos consumidores.

Pela necessidade de se prover água aos consumidores dos sistemas públicos de abastecimento dentro dos modelos instituídos pela legislação vigente, a Portaria 518 do Ministério da Saúde, tendo como objetivo a satisfação dos consumidores, os encarregados pela operação dos sistemas de tratamento e controle de qualidade, carecem de concentrar técnicas de tratamento adequadas para a manutenção do produto dentro dos limites estabelecidos. A legislação vigente por meio da Resolução do Conselho Nacional de Meio Ambiente - Conama No. 357/2005 e da Portaria do Ministério da Saúde - MS N².914/2011 estabelece 0,3 mgFe.L-1 como o Valor Máximo Permitido - VMP - para o quantitativo de ferro na rede de abastecimento.

O estudo realizado pretendeu responder à seguinte problemática: é viável a utilização do processo de filtração por zeólita para remover o ferro nas águas da nascente Serra do Andrade - Minas Gerais? Segundo Fonseca at al (2020), é notável o descaso humano sobre assuntos relacionados ao meio ambiente, ressalta ainda que a humanidade durante décadas poluiu e utilizou os recursos naturais sem se preocupar com a sustentabilidade.

Nesse sentido, o objetivo geral da pesquisa foi propor um processo alternativo para a remoção de Fe nas águas da nascente, por meio de filtração adsortiva com a aplicação do material adsorvente (zeólita), disponível comercialmente. Os objetivos específicos foram: avaliar a possibilidade da remoção do ferro por meio da filtração zeólita; avaliar o efeito do ph na eficiência da filtragem. Para tanto, foi necessário levantar, no local da investigação, dados de caracterização da qualidade da água e de geoquímica relacionados com a temática da pesquisa, além da coleta de dados técnicos da área de estudo. 
Tal estudo se justifica pela necessidade dos sistemas de abastecimento adotar processos e métodos para o tratamento adequado da água, quando se verifica a presença de metais acima do limiar permitido por lei. Com isso, esta pesquisa busca caracterizar uma alternativa eficiente para os métodos de tratamento e controle da água, demonstrando seus resultados.

\section{Metodologia}

O presente estudo se desenvolveu através de uma pesquisa descritiva, que segundo Gil (2010) é aquela que se propõe a estudar um fenômeno que se deseja melhor compreender. O estudo se deu por meio de procedimentos experimentais, através de uma abordagem exploratória e quantitativa de um estudo de caso.

O mesmo autor (2010) afirma ainda que a pesquisa experimental consiste em determinar um objeto de estudo, selecionar as variáveis que seriam capazes de influenciá-lo, definir as formas de controle e de observação dos efeitos que a variável produz no objeto (Gil, 2010).

Nesse contexto, a Figura 1 apresenta um fluxograma com as etapas do estudo.

Figura 1 - Fluxograma Etapas do estudo.

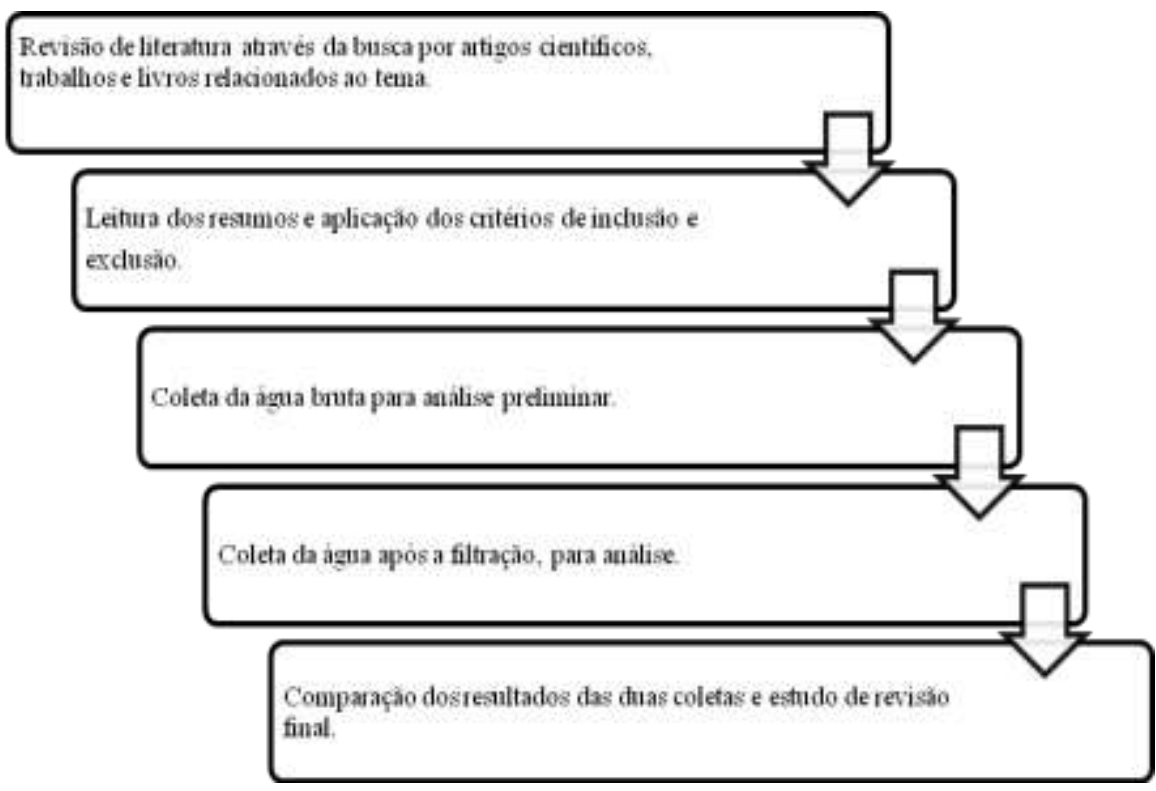

Fonte: Autores da pesquisa (2021).

O embasamento teórico se pautou em informações científicas pesquisadas em livros e artigos científicos, disponíveis de forma impressa e eletrônica. Ao final do estudo, com base nas análises e inferências, foram feitas sugestões para melhorias. Em relação à classificação da pesquisa, quanto à sua natureza esta essa se classificou como aplicada.

\subsection{Material e Métodos}

O local da realização da pesquisa e análise do experimento foi a Nascente Serra do Andrade, localizada em João Monlevade - Minas Gerais como mostra a Figura 2. 
Figura 2 - Localização do Município de João Monlevade.

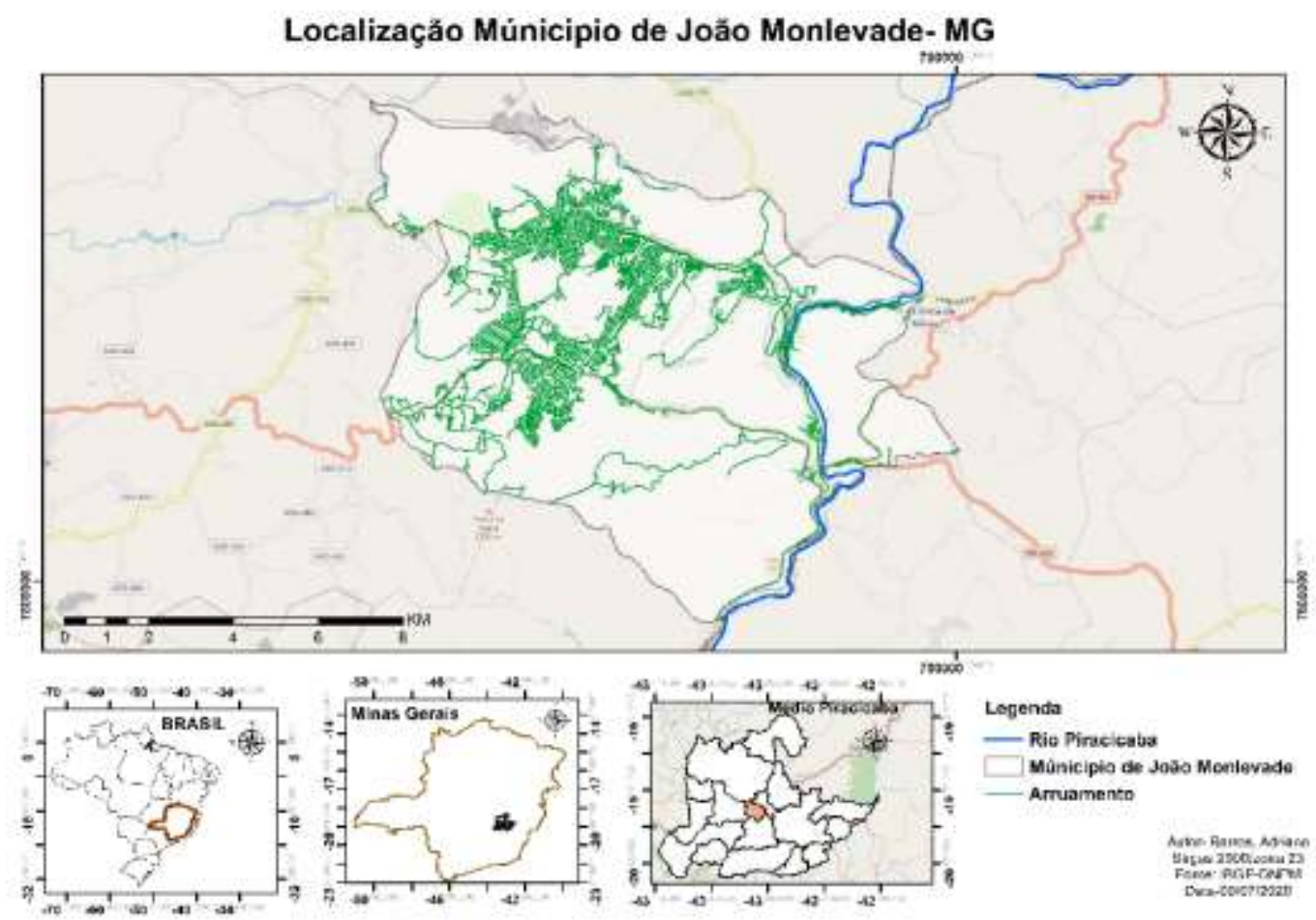

Fonte: Autores da pesquisa (2021).

A zeólita utilizada para o estudo foi do tipo Zeólita para remoção de ferro e manganês $(0,4$ a $1,2 \mathrm{~mm}$ - saco de 25 KG), como mostra a Figura 3. Esse tipo de material é composto por um meio filtrante granulado de elevada quantidade de minerais ativos, com alto desempenho para remoção de ferro, em águas industriais, potáveis e minerais. A zeólita funciona como um catalisador, capturando os elementos indesejáveis, ferro, manganês e sulfeto de hidrogênio, no interior da mídia. A sua eficiência é comprovada em testes de desempenho para remoção seletiva de todos os contaminantes descritos acima.

Figura 3 - Zeólita comercial para remoção de Ferro.

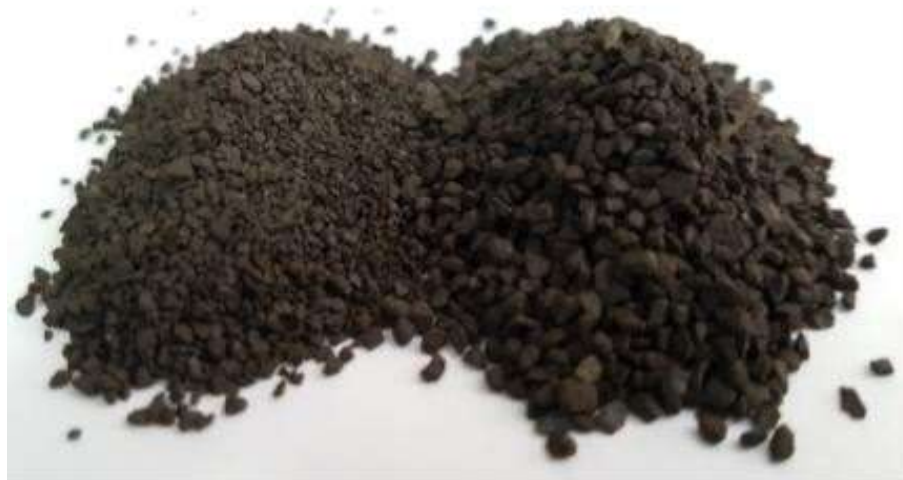

Fonte: http://www.lojaeraambiental.com.br.

Entre as principais vantagens da utilização dessa zeólita podemos destacar: 
a) A não necessidade de utilização de regenerantes químicos.

b) Baixo custo operacional.

c) Elevada resistência mecânica, possibilitando a baixa geração de finos por atrito, no processo de retrolavagem ou mesmo pela pressão interna do vaso.

d) Elevada vida útil (acima de cinco anos), devido ao baixo desgaste da mídia durante o processo de remoção das impurezas.

A zeólita utilizada como material para a parte prática da pesquisa possibilitou a remoção dos citados metais através de um meio filtrante à base de zeólitos naturais e sintéticos ativados, onde a remoção do ferro se deu pelo processo de oxidação e adsorção.

Com o material revisado foi elaborada uma análise critica para melhor utilização do filtro zeólita. Mediante aos dados coletados e analisados foi feito um estudo sobre as diversas metodologias com o propósito de identificar e analisar quais os resultados obtidos com a filtragem da água a partir do método zeólita.

Com o objetivo de se avaliar esse tipo de filtração, foi desenvolvido este estudo, que visou quantificar os índices de ferro total da água bruta da nascente, comparando-os com os índices finais da água pós-filtração.

A Figura 4 ilustra a coleta da água e os recipientes utilizados na prática.

Figura 4 - Coleta da água bruta.

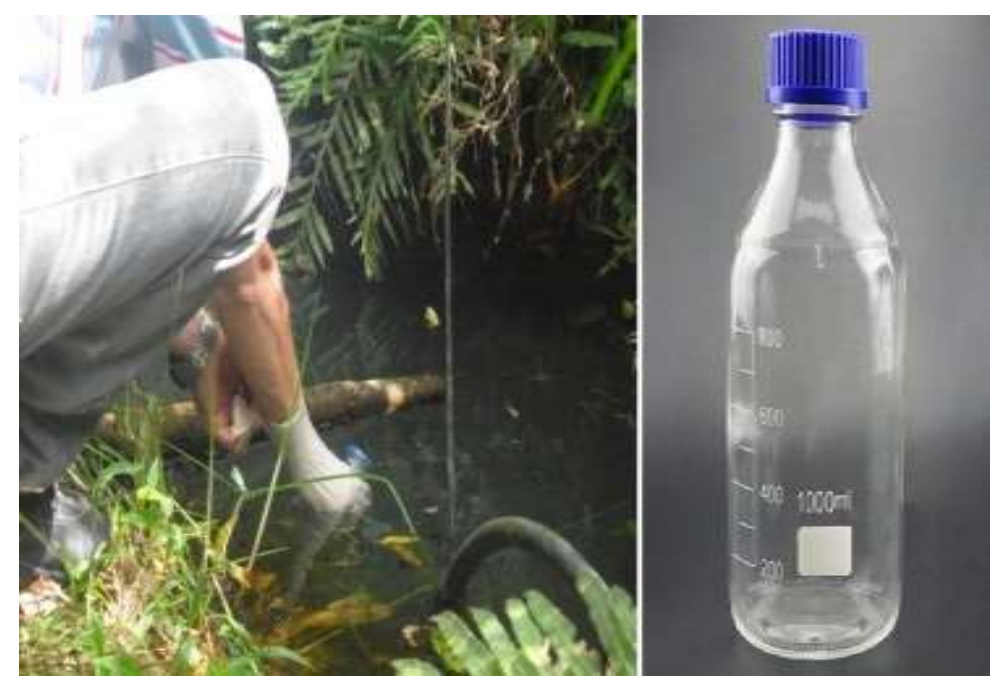

Fonte: Autores da pesquisa (2021).

Para este estudo, foram empregados as análises das águas da nascente citada, cujos perfis geológicos apresentam formações do tipo Caçapava e embasamento cristalino, tendo como características diferenciais a presença de ferro total na composição química de suas águas.

Inicialmente, foi feita uma coleta da água através de um vasilhame tipo béquer. Foi realizada, em primeiro momento, uma filtração por pressão somente para limpeza e adequação do meio filtrante. A segunda etapa da coleta de amostras foi realizada no período da manhã. A Figura 5 ilustra a segunda a prática da coleta. Já a Figura 6 mostra a zeólita sendo utilizada como meio filtrante. 
Figura 5 - Etapas da coleta de água.

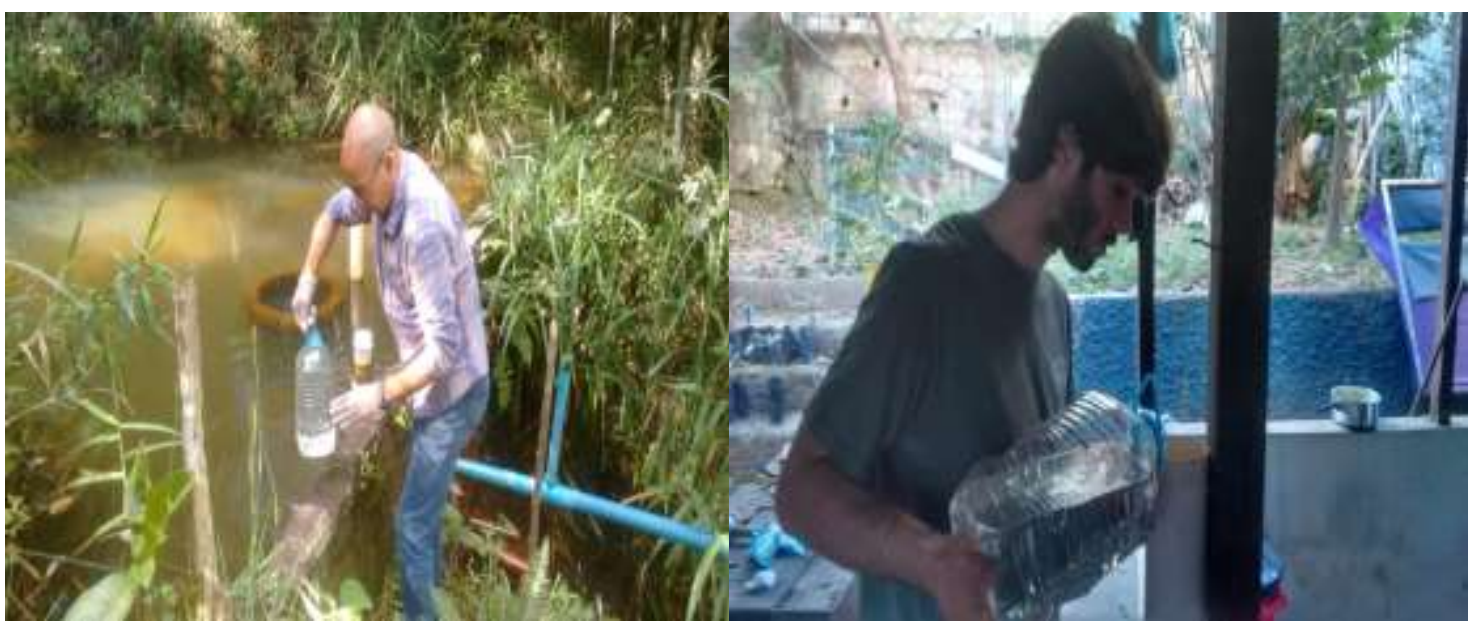

Fonte: Autores da pesquisa (2021).

Figura 6 - Zeólita como meio filtrante.

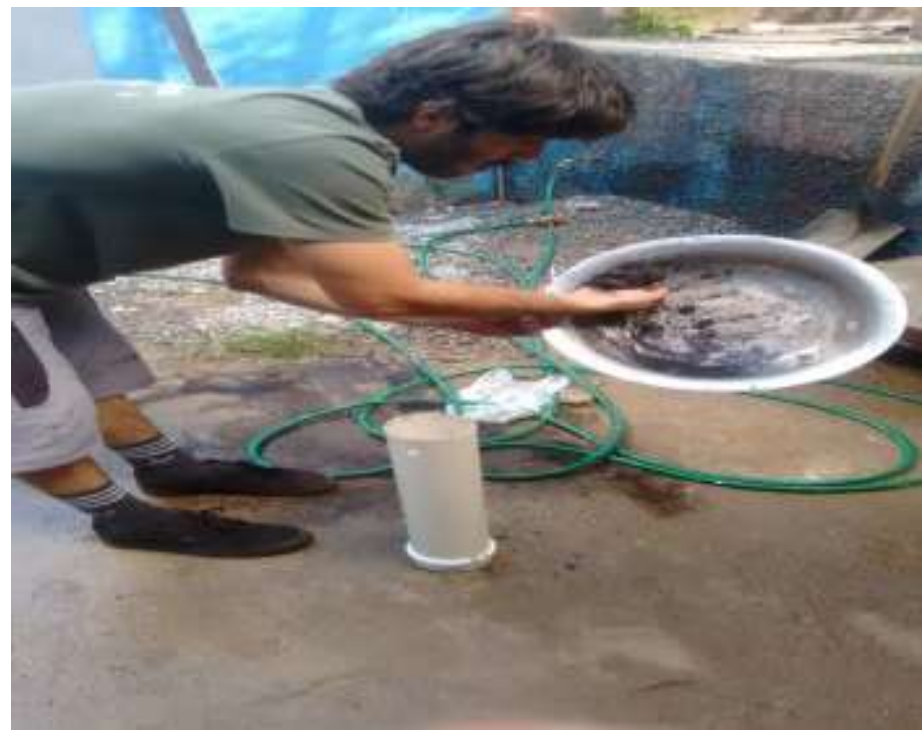

Fonte: Autores da pesquisa (2021).

Foram analisados os parâmetros ferro total, após a segunda etapa da prática. Os dados foram tabulados e organizados numa tabela, para que pudessem ser mais bem visualizados e compreendidos. Uma vez organizados, foram analisados à luz do referencial teórico estudado.

\section{Referencial Teórico}

Segundo Victorino (2007), a água é o principal elemento constituinte da vida no planeta Terra, essencial para o funcionamento dos ecossistemas e da vida, recurso natural que possui papel fundamental na economia dos agrupamentos humanos, de grande utilidade para o abastecimento público, industrial, agropecuária, produção de energia elétrica e atividades de lazer e recreação, bem como para a preservação da vida aquática. Nesse sentido Almeida at al (2020) enfatiza que a necessidade de compreender e refletir sobre as problemáticas do uso descontrolado dos recursos naturais.

Segundo Cali e Costa (2020), ainda não está evidente para a maior parte das pessoas que a água é um bem finito e que depende de ações não somente sob a perspectiva do seu uso racional como também sua preservação, sobretudo ela também depende de políticas de implementação do direito ao saneamento básico. Dito de outra forma: além das pessoas, a água (e a 
Research, Society and Development, v. 10, n. 6, e59910615980, 2021

(CC BY 4.0) | ISSN 2525-3409 | DOI: http://dx.doi.org/10.33448/rsd-v10i6.15980

natureza em sua plenitude) também precisa ser protegida com ações sustentáveis, a partir de mudanças de comportamento e com o desenvolvimento de instrumentos tecnológicos que tornem a implantação dos serviços de saneamento básico mais acessível para todos.

Nesse contexto, a distribuição desigual pelo território e a crescente expansão demográfica e industrial observadas nas últimas décadas trouxeram como decorrência o uso e abuso dos recursos hídricos, comprometendo a qualidade desse recurso e proporcionando um quadro de escassez da água potável que se avizinha, conforme relata (Victorino, 2007).

De início, o consumo de água pelo homem estava praticamente limitado aos usos essenciais à manutenção da vida: bebida e preparo de alimentos. Todo sistema de abastecimento de água deve ter por objetivo distribuir a água com o mínimo de risco possível para que uma pessoa razoavelmente informada sinta segurança em bebê-la. Ainda nesse contexto, Moreno (1996) afirma que como parte das políticas públicas voltadas para água e saúde, é necessário considerar a situação de saúde pública em geral e a contribuição que a qualidade da água produzirá no controle de doenças de transmissão hídrica e, também, a importância de garantir o acesso à água potável, especialmente para as populações ainda não beneficiadas.

Segundo Freire e Pereira (2005) o Brasil possui aproximadamente doze por cento da água doce disponível no mundo sendo considerado um país com privilégios pelo seu estimado recurso hídrico. Estudos foram feitos e foi considera-se que aproximadamente até o final do século passado, a água fora considerada um bem inesgotável, porém esta concepção tornou-se equivocada devido às mudanças do clima, e principalmente, mudanças decorrentes às atividades humanas, desmatamento, emprego indiscriminado de produtos agrícolas, assoreamento de rios e nascentes, impermeabilização de solos, entre outros, além da falta de planejamento urbano.

\subsection{Características das águas naturais}

Alguns fatores físicos, químicos e biológicos podem classificar a água de acordo com suas características. Segundo Vistuba (2010), algumas características como a cor e turbidez geralmente tem sua origem de pequenas partículas suspensas na água. Já fatores como odor e sabor estão ligados às impuridades de origem orgânica como resíduos industriais entre outros. O mesmo autor em seus estudos cita a temperatura como outra característica que por sua vez influencia outras propriedades da água, aumentando sua turbidez e a cor (Vistuba, 2010).

De forma direta a condutividade elétrica está ligada à presença de sais dissolvidos na água. Estes sais, presentes de maneira exacerbada podem favorecem a corrosão das tubulações de distribuição. Já o pH sugere o grau de acidez e neutralidade (Vistuba, 2010).

A Dureza segundo Vistuba (2010) é determinada pela presença de sais de cátions polivalentes alcalino-terrosos e outros metais em menor grau, tais como os bicarbonatos, sulfatos e cloretos de cálcio, magnésio, dentre outros. Já o ferro e Manganês são elementos que conferem à água um sabor de gosto forte e adstringente com coloração marrom-amarelada e turva, decorrente da oxidação dos mesmos, constituindo um precipitado.

De acordo com Azevedo e Fernandes (1988) outra característica importante a ser citada é o fator biológico, já que a água é um veículo na transmissão de doenças. As impurezas presentes na água incluem os microrganismos como bactérias, vírus, protozoários e as algas, que provocam sabor e odor desagradáveis, além de interferir em etapas do tratamento, como na obstrução de filtros. Estes parâmetros podem ser determinados por meio de exames bacteriológicos e hidrobiológicos.

No instante em que a água é retirada da sua fonte natural e é tratada para abastecimento público, ela normalmente é exposta a bombeamento, aeração e reações químicas diversas, o que pode levar à sua desestabilização, criando oportunidades de corrosão ou incrustação em seu percurso. 
Sendo assim, a respeito dos tratamentos realizados, a rede de distribuição pode aferir cor à água já tratada, a depender da idade, material da rede, das condições de $\mathrm{pH}$, da apresentação de incrustações associadas a íons de ferro e manganês, e principalmente quando da ocorrência de intermitência no abastecimento de água (Vistuba, 2010).

Com o objetivo de diminuir os problemas de coloração da água, podem ser realizadas descargas em pontos da rede de distribuição. Contudo, com este procedimento, ocorre um aumento das perdas de água do sistema.

Prianti et al (2003) citam também a possibilidade de remoção de ferro e manganês por um processo de filtração da água através de um meio filtrante à base de zeólitos naturais e sintéticos ativados, onde a remoção desses metais se daria pelo processo de oxidação e adsorção. Este parâmetro não tem significado sanitário para água potável, mas em elevadas concentrações confere um gosto amargo para água. É uma deliberação importante no controle do tratamento da água, estando relacionada com a coagulação, redução de dureza e prevenção da corrosão em tubulações.

Para controle ou remoção de ferro da água, pode-se utilizar um processo de aeração, sedimentação e filtração conjugado ao uso de oxidantes como o cloro, dióxido de cloro, ozônio e alcalinizante (Di Bernado,1993).

Em seus estudos Carmo (2013) afirma que o aerador de tabuleiro é o mais indicado para a adição de oxigênio e, consequentemente, oxidação de compostos ferrosos ou manganosos. O mesmo autor (2013) afirma também que os métodos usualmente empregados para remoção de manganês e de ferro incluem a formação de precipitado e filtração, troca iônica e estabilização com polifosfatos. No caso de formação de precipitado e filtração, pode ser empregada a aeração, sedimentação e filtração, ou a oxidação com permanganato de potássio, cloro e dióxido de cloro, seguida de filtração. Tanto quanto se conhece, o ser humano não sofre qualquer efeito danoso quando ingere água contendo manganês (Carmo, 2013).

Tanto ferro quanto manganês podem estar presentes nas águas superficiais e subterrâneas na forma solúvel e insolúvel, não complexados e complexados a minerais ou a compostos orgânicos. Quando se encontram na forma solúvel, complexados ou não à matéria orgânica natural, podem, no primeiro caso, ser catiônicos ou aniônicos.

Segundo Lima (2003), o ferro é o elemento telúrico mais abundante, compondo 30\% da massa total do planeta. Constitui $80 \%$ do núcleo e é o quarto elemento mais abundante da crosta terrestre, depois do oxigênio, silício e alumínio. Ao lado do alumínio, é o mais importante elemento metálico no ambiente terrestre. Uma pequena parte ocorre no estado livre sendo de origem meteórica, mas a maior parte aparece combinada com oxigênio, silício ou enxofre. Quase todas as rochas e solos contêm pelo menos traços de ferro.

Carmo (2003) afirma que a cor da água é o resultado principalmente dos processos de decomposição que ocorrem no meio ambiente. Por este motivo, as águas superficiais estão mais sujeitas a ter cor do que as águas subterrâneas. Além disso, pode-se ter cor devido à presença de alguns íons metálicos, como ferro e manganês, plâncton, macrófitas e despejos industriais.

\subsection{Ferro em águas naturais}

Os sais dissolvidos na água ou no sedimento são essenciais aos organismos vivos. Alguns desses sais são necessários em quantidades moderadas, tais como os sais de cálcio, magnésio, potássio e ferro, e outros devem ser consumidos em menor quantidade como o manganês, zinco, cobre, molibdênio e cobalto (Zambetta, 2006).

Os efeitos de uma substância química, especificamente dos metais, sobre a biota dependem da forma física e química desses metais no sistema, ou seja, da sua especiação (Sodré, 2005).

Segundo Bury e Grosell (2003) a nível celular, o ferro catalisa algumas reações, resultando na geração de radicais livres de oxigênio, particularmente o radical hidroxila, que potencialmente pode causar dano oxidativo celular. 
$\mathrm{Na}$ água, a especiação do Fe, isto é, a maneira como este elemento se encontra, pode ser na forma livre ou complexada, como íon divalente (+2) ou trivalente $(+3)$, em estado coloidal ou disperso. Em condições de aerobiose, os íons ferrosos ( $\mathrm{Fe}+2)$, que são solúveis, são convertidos a íons férricos ( $\mathrm{Fe}+3)$ formando hidróxidos de ferro insolúveis.

De acordo com Lima e Pedrozo (2001) a ingestão de Fe, quando 5 a 10 vezes maior que a necessária, pode causar lesões no pâncreas com aparecimento de diabetes, incidência de carcinoma hepático e pigmentação na pele.

\subsection{Remoções de ferro continuar conferindo a formatação.}

\subsubsection{Métodos convencionais de remoção de Fe}

De acordo com El Araby et al (2009) as metodologias convencionais de retirada do Fe (II) diluídos via precipitação, comumente promovem a utilização de oxidantes fortes, como permanganato de potássio, cloro, hipoclorito de sódio, dióxido de cloro ou ozônio, para desenvolver compostos insolúveis de Fe (III) que são movidos via decantação e/ou filtração. No entanto, múltiplos desses reagentes podem formar arranjados indesejáveis e muito nocivos à população, como por exemplo, trihalometanos que são virtualmente cancerígenos.

Vagliasindi et al., (2007) afirma que outro procedimento de retirada desses elementos, denominada oxidação através de aeração, seguida de filtração, distinguir-se por ser um técnica lenta, a menos que o valor do pH esteja acima da neutralidade. Além disso, o resíduo gerado precisa ser neutralizado antes do lançamento nos corpos hídricos.

Os métodos convencionais de remoção de íons metálicos em águas muitas vezes se tornam inviáveis na prática, devido ao aumento do número de etapas a serem realizadas em uma ETA. Por exemplo, após um processo de precipitação de íons, sejam na forma de hidróxidos, óxidos, carbonatos ou sulfatos, é necessária a filtração dos sólidos suspensos e a clarificação da água tratada.

A biotecnologia tem recebido muita atenção nos últimos anos e gradualmente está se tornando uma ótima alternativa para o controle e remoção de metais devido ao seu grande potencial de aplicação. O processo de biossorção é um exemplo dessa biotecnologia, pois utiliza espécies naturais incluindo bactérias, fungos e algas denominados de biossorventes.

Este processo pode ser definido como a remoção biológica de espécies metálicas e metalóides. O mecanismo responsável pela biossorção pode estar associado aos processos de troca iônica, complexação, adsorção, interações eletrostáticas, microprecipitação, entre outros (Vijayaraghavan \& Yun, 2008).

Os biossorventes têm a propriedade de sequestrar os metais e diminuir a concentração dos mesmos. Estes biossorventes podem sequestrar com muita eficiência e rapidamente os íons metálicos em soluções complexas, sendo também ideais para os tratamentos de águas residuárias. A capacidade desses microrganismos em acumular elementos metálicos foi observada primeiro sob o ponto de vista toxicológico.

Porém, pesquisas revelaram que a biomassa microbiana inativa/morta pode passivamente ligar metais via mecanismos físicoquímicos. Alguns tipos de biossorventes têm a capacidade de assimilar qualquer tipo de metal, enquanto outros são mais específicos (Wang \& Chen, 2009).

A aplicação de filtros biológicos em ETAs é uma alternativa viável para a remoção de contaminantes. No caso da remoção de Fe, uma ampla variedade de bactérias é conhecida por catalisar a oxidação destes elementos, formando óxidos de ferro, que ficam retidos no material suporte, sem a necessidade de posterior clarificação da água. Em particular, a oxidação pode ser feita por bactérias do gênero Leptothrix, Crenotrix, Hyphomicrobium, Siderocapsa, Metallogenium, Pseudomonas spp, Bacillus sp. (Tekerlekopoulou et al, 2008). 
Algumas diferenças entre o processo de oxidação biológica e os métodos físicos químicos convencionais são os baixos custos na operação, devido à probabilidade da filtração ser concretizada de maneira singular em um único estágio e sem a aplicação de produtos químicos (Takeda et al., 2009).

\subsubsection{Métodos não convencionais de remoção de $\mathrm{Fe}$}

Muitos são os produtos e técnicas desenvolvidas para a remoção de contaminantes, que visam sua aplicação em escala real. Atualmente, estão disponíveis algumas técnicas e materiais capazes de remover Fe. Dentre eles, podem ser citados:

\section{- Filtração biológica}

Nos últimos tempos a biotecnologia vem ganhado destaque tornando-se uma boa opção no controle e remoção de metais em virtude do seu alto poder de aplicação. O processo de biossorção pode ilustrar essa biotecnologia, porque usa espécies naturais incluindo bactérias, fungos e algas nomeadas de biossorventes. Este procedimento pode ser determinado como a retirada biológica de espécies metálicas e metalóides. A estrutura responsável pela biossorção pode estar associada a metodologias de troca iônica, complexação, adsorção, interações eletrostáticas, microprecipitação, entre outros (Vijayaraghavan \&Yun, 2008).

Uma opção viável para a remoção de contaminantes é o aproveitamento de filtros biológicos em Estações de Tratamento. Se tratando da retirada de $\mathrm{Fe}$, uma extensa multiplicidade de bactérias é distinguida por catalisar a oxidação destes elementos, formando óxidos de ferro, que ficam detidos no material base, sem a obrigação de futura clarificação da água. Particularmente, a oxidação pode ser feita por bactérias do gênero Leptothrix, Crenotrix, Hyphomicrobium, Siderocapsa, Metallogenium, Pseudomonas spp, Bacillus sp. (Tekerlekopoulou et al, 2008).

Uma das principais desvantagens desse processo é o longo período de tempo requerido para o desenvolvimento e estabilização do biofilme bacteriano, na ordem de meses. Além disso, é importante o controle criterioso das condições operacionais, tendo em vista a sensibilidade das bactérias às condições ambientais (Tekerlekopoulou et al, 2008).

\section{- Filtração em membranas}

A principal novidade tecnológica nos processos de tratamento de água e esgoto é o procedimento de filtração em membranas. Tal tecnologia dispõe de uma vasta diversidade de aproveitamentos e isto não é notado em outros processos. No entanto, o aproveitamento das membranas dependerá das propriedades da água a ser tratada, sendo muitas vezes necessário um pré-tratamento para evitar a colmatação dos poros da membrana, que enfraquece o efeito e pode até gerar sua inutilização (Schneider \& Tsutiya, 2001).

As membranas são compostas de material polimérico ou cerâmico, que exibem diversas porosidades. Estes poros são responsáveis por todas as características que tornam as membranas úteis em suas diversas aplicações, tanto para separar partículas não dissipadas como para fracionar moléculas dissolvidas de diferentes massas molares. Como barreiras seletivas que atuam como uma espécie de filtro, as membranas são capazes de promover separações em sistemas onde os filtros comuns não são eficientes (Dias, 2006).

Apesar disso, a remoção através da membrana só ocorre se ocorrer a pré-oxidação dos elementos, sendo necessário acrescentar reagentes químicos para a formação de óxidos de manganês e ferro antes da 35 filtração aumentando ainda mais o valor da operação (Vagliasindi et al., 2007). 


\subsubsection{Zeólita utilizada como meio filtrante}

As zeolitas são compostas por um esqueleto tridimensional de tetraedros de $\mathrm{SiO} 4$ e $\mathrm{AlO} 4$. Elas possuem cavidades e canais regulares e de tamanho molecular, nos quais pode haver passagem de moléculas de água. O desbalanceamento de cargas provocado pelo Al estrutural, que é trivalente, é compensado por cátions de metais alcalinos e alcalinos terrosos. Esta categoria atribui às zeólitas a característica de troca iônica (Dal Bosco et al, 2004).

Segundo Vistuba (2010), as zeólitas têm a capacidade de trocar íons presentes na água, auxiliando na remoção de íons como cálcio e magnésio, diminuindo a dureza das mesmas. Além disso, são excelentes para a remoção de íons metálicos, devido às suas propriedades físico-químicas, tais como, cristalinidade, estabilidade térmica, cadeia bem definida, seletividade iônica. Além disso, é destacável a possibilidade de reutilização sem perder a capacidade de adsorção. A Figura 7 mostra a zeólita comercializada.

Figura 7 - Zeólita

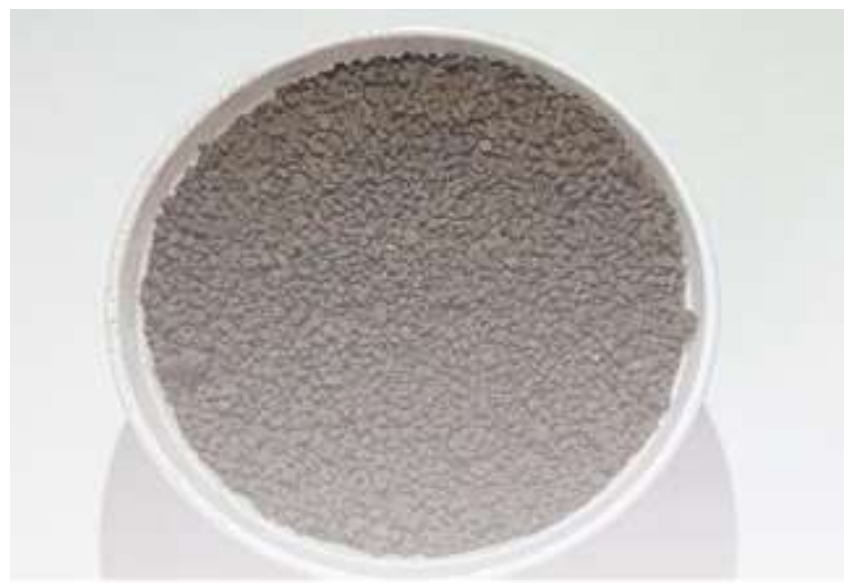

Fonte: Legner, (2019, p. 15).

As zeólitas naturais têm baixa capacidade de troca-iônica e são comumente tratadas por métodos químicos ou físicos após serem utilizadas. As soluções de cloreto de sódio são amplamente empregadas para ativar zeólitas e aumentar a sua capacidade de adsorção (Taffarel \& Rubio, 2009).

A zeólita Controll MF 574® é um exemplo de material adsorvente. Esta zeólita é fabricada pela empresa Controll Master Industrial, situada em Sete Lagoas - MG. Este material é um meio filtrante catalítico, esterilizado e ativado, à base de zeólitas naturais e sintéticas. Apresenta uma coloração escura e forma granular. O tempo de vida útil estimado para este material é de oito anos. $\mathrm{O}$ valor ideal de $\mathrm{pH}$ para a remoção de metais, indicado pelo fornecedor, é superior a 6,5.

Diante do que foi exposto, a técnica escolhida no presente estudo para a remoção de Fe das águas de abastecimento foi a filtração adsortiva, uma vez que a tecnologia de membranas é ainda extremamente cara e os meios filtrantes existentes para filtração convencional não estão disponíveis no Brasil em grande escala ou requerem reagentes químicos para sua regeneração.

Além disso, esses materiais apresentam uma vida útil elevada, o que pode ser visto como uma vantagem especialmente se for aplicados em uma estação de tratamento de água em escala real.

A Figura 8 mostra a microscopia eletrônica de varredura da zeólita Controll M.F. 574® com magnificação de 33 vezes (a) e 10.000 vezes (b). 
Figura 8 - Microscopia da zeólita.
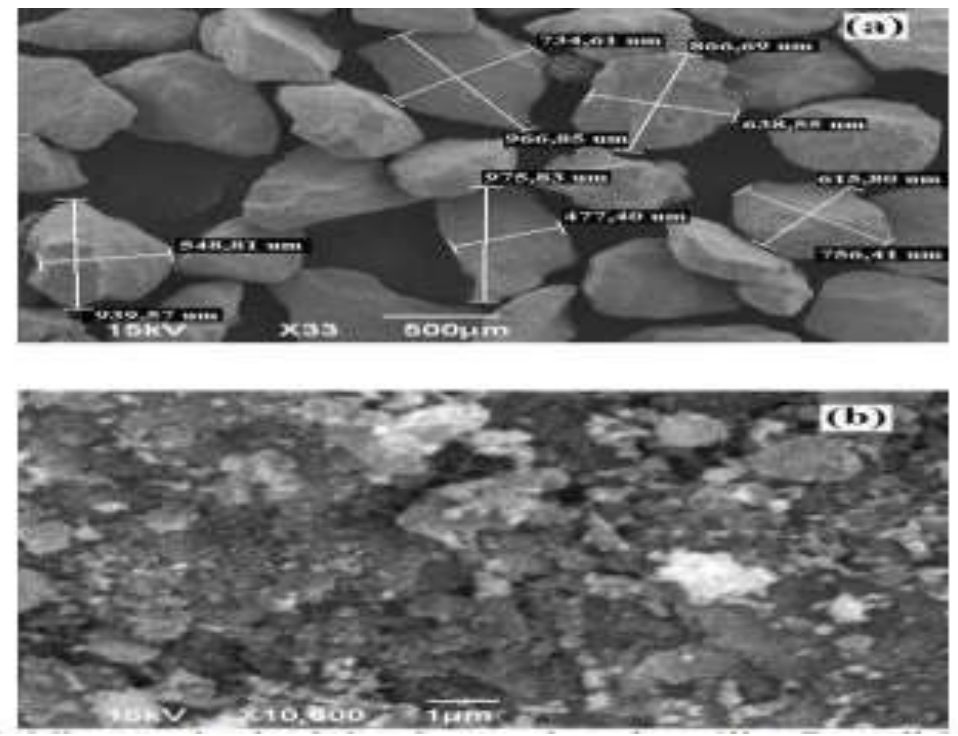

Fonte: Vistuba, (2010. p. 53).

\section{Resultados e Discussão}

\subsection{Caracterização da água bruta}

Com relação à prática realizada com a água, nas duas análises observou-se a presença de ferro total acima do limite de $0,3 \mathrm{mg} / \mathrm{L}$, como mostra a Tabela 1 na primeira análise. Esse valor foi reduzido através do uso da zeólita, ficando dentro dos parâmetros como mostra a Tabela 2.

Tabela 1 - Resultados da água bruta.

\begin{tabular}{|c|c|c|c|c|c|c|}
\hline Ensaio & Resultado & Unidade & $\begin{array}{c}\text { Limite } \\
\text { aceitável (L) }\end{array}$ & LQ & Método & $\begin{array}{c}\text { Data do } \\
\text { Ensaio }\end{array}$ \\
\hline $\begin{array}{c}\text { Ferro } \\
\text { Total }\end{array}$ & 0,614 & $\mathrm{mg} / \mathrm{L}$ & $0,3\left({ }^{*} \mathrm{FeMn}\right)$ & 0,001 & $\begin{array}{c}\text { SMEWW 23RD } \\
\text { ed. 3120 B }\end{array}$ & $08 / 08 / 19$ \\
\hline
\end{tabular}

Fonte: Autores da pesquisa (2021).

Tabela 2 - Resultados da água após o uso da zeólita.

\begin{tabular}{|c|c|c|c|c|c|c|}
\hline Ensaio & Resultado & Unidade & $\begin{array}{c}\text { Limite } \\
\text { aceitável (L) }\end{array}$ & LQ & Método & $\begin{array}{c}\text { Data do } \\
\text { Ensaio }\end{array}$ \\
\hline $\begin{array}{c}\text { Ferro } \\
\text { Total }\end{array}$ & 0,23 & $\mathrm{mg} / \mathrm{L}$ & $0,3\left({ }^{*} \mathrm{FeMn}\right)$ & 0,02 & $\begin{array}{c}\text { SMEWW 23RD } \\
\text { ed. 3120 B }\end{array}$ & $08 / 08 / 19$ \\
\hline
\end{tabular}

Fonte: Autores da pesquisa (2021).

Na Tabela 2, avaliando os dados da água após o tratamento, observou-se uma redução considerável de ferro total estando esse de acordo com o estabelecido pela legislação. No gráfico da Figura 9 são apresentados os resultados de ferro total da água bruta, bem como os resultados pós-filtração, observando-se uma redução de 62,54\% desse metal na água final. 
Comparando-se o método de filtração descrito com os processos tradicionais para remoção de metais que incluem aeração e decantação, verifica-se sua aplicabilidade em virtude do alto poder de redução do ferro atingido através das análises e pela água pós filtração não necessitar de pré-cloração, tendo assim uma diminuição do tempo de trabalho operacional e do consumo de água para limpeza, devido à eliminação das etapas referentes à aeração e decantação.

Figura 9 - Valores médios de ferro total da água bruta e pós filtração.

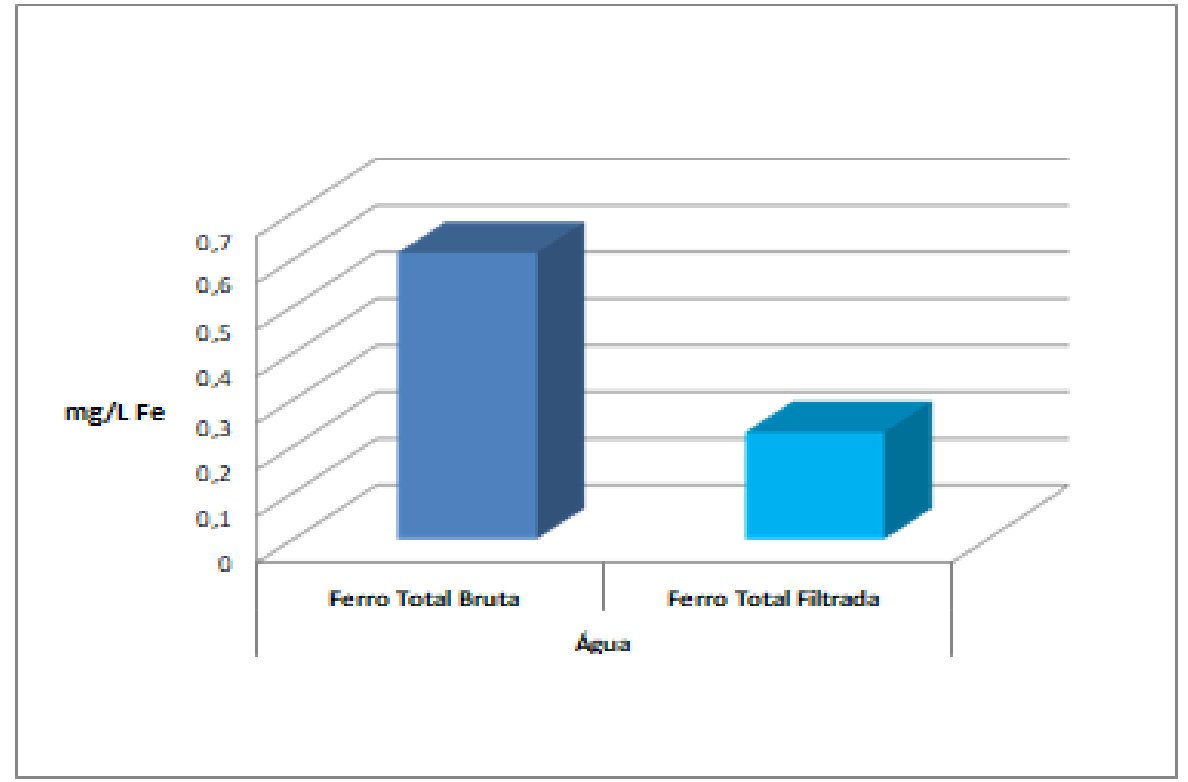

Fonte: Autores da pesquisa (2021)

\section{Considerações Finais}

Para a aplicação de qualquer técnica para minimização de problemas em águas para consumo humano, é importante avaliar: a problemática; a quantidade de água a ser tratada; a qualidade da água captada; o tipo de manancial; os custos de implantação e manutenção do sistema, e os custos indiretos referentes à imagem da empresa junto aos consumidores. Nesse sentido, consideramos que o maior ganho na utilização da zeolita como meio filtrante tenha sido a manutenção da água dentro dos padrões organolépticos de qualidade e, consequentemente, maior confiabilidade por parte do usuário na água consumida.

Este estudo apresentou a problemática da presença de ferro em águas naturais. Foram abordados os aspectos relativos à ocorrência, formas predominantes, problemática, e remoção do ferro. Diversos oxidantes podem ser utilizados, porém, a melhor alternativa de tratamento depende das concentrações de ferro presente. Quanto à remoção do ferro, diversas tecnologias podem ser empregadas sendo recomendado um estudo prévio visando definição da melhor alternativa.

No caso deste estudo, a alternativa pelo método da zeólita se mostrou altamente eficiente, em virtude do alto índice de redução do ferro que estava presente na amostra com a água bruta.

Diante do exposto, sugere-se para trabalhos futuros o emprego de novos ensaios para a análise do pH sob ação da zeólita, a fim de avaliar o potencial de precipitação dos íons de ferro sob diferentes condições de $\mathrm{pH}$.

\section{Referências}

Almeida, F. C. P.,Menezes, M. A.,Facó, J. F. B.(2020). Desafios na gestão das águas: percepção dos gestores de uma indústria automotiva da Macrometrópole Paulista. Research, Society and Development, 9(2), e02921920. http://dx.doi.org/10.33448/rsd-v9i2.1920 
Brasil. (2011). Ministério da Saúde. Portaria No 2914/2011. Dispõe sobre os procedimentos de controle e de vigilância da qualidade da água para consumo humano e seu padrão de potabilidade. Diário Oficial [da] União, 12 dez. 2011. http://bvsms.saude.gov.br/bvs/saudelegis/gm/2011/prt2914_12_12_2011.html.

Brasil (2005). Resolução CONAMA 357 de 17 de março de 2005. Dispõe sobre a classificação dos corpos de água e diretrizes ambientais para o seu enquadramento, bem como estabelece as condições e padrões de lançamento de efluentes, e dá outras providências.

http://www2.mma.gov.br/port/conama/legiabre.cfm?codlegi=459

Bury, N. \& Grosell, M. (2003). Iron acquisition by teleost fish. Comparative Biochemistry and Physiology. ScienceDirect 135(97-105). https://www.sciencedirect.com/science/article/abs/pii/S1532045603000218

Carli, A.A \& Costa, L.A. (2020). Água potável e saneamento básico: o encontro necessário de dois direitos fundamentais à saúde da vida em geral. Revista de Direito e Sustentabilidade 6(2). https://indexlaw.org/index.php/revistards/article/view/6353.

Carmo, R. F, \& Bevilacqua, P.D. (2013). Vigilância da qualidade da água para consumo humano: abordagem qualitativa da identificação de perigos. Revista de Engenharia Sanitária e Ambiental. 13(4). https://doi.org/10.1590/S1413-41522008000400011.

Dal, B. S. M, Jimensez, R. S, \& Carvalho, W.A. (2004). Aplicação da zeólita natural escolecita na remoção de metais pesados de efluentes industriais: competição entre os cátions e processo de dessorção. Ecletica Química. 29(1), 47-56. https://www.scielo.br/scielo.php?script=sci_arttext\&pid=S010046702004000100006

Bernardo. L. Di. (1993). Métodos e técnicas de tratamento de Água. Rio de Janeiro: ABES.

Dias, T. (2006). Membranas: meio filtrante de tecnologia avançada. Revista Meio Filtrante (5) 23. https://meiofiltrante.com.br/Artigo/1120/membranasmeio-filtrante-de-tecnologia-avancada.

El Araby, R., Hawash, S. e El Diwani, G. (2009).Treatment of iron and manganese in simulated groundwater via ozone technology.Desalination. Open Access Library Journal, 7(3), 1345-1349. https://scirp.org/reference/referencespapers.aspx? referenceid=2706187

Fonseca, P. F. Silva, J. R.,\& Fonseca, E.S.(2020). Análise da viabilidade da separação de água de chuveiros e pias para reúso. Research, Society and Development, 9(2), e14921938, (CC BY 4.0). http://dx.doi.org/10.33448/rsd-v9i2.1938\%2011

Freire, R. S., \& Pereira, W. S. (2005). Ferro Zero: uma nova abordagem para o tratamento de águas contaminadas com compostos orgânicos poluentes. Química Nova, 28(1), 130-136. https://www.scielo.br/scielo.php?pid=S0100-40422005000100022\&script=sci_abstract\&tlng=pt.

Gil, A.C. (2010). Métodos e técnicas de pesquisa social. São Paulo: Atlas.

Lima, I.V., \& Pedrozo, M.F. (2001). Ecotoxicologia do ferro e seus compostos. https://livrozilla.com/doc/906578/ecotoxicologia-do-ferro-e-seuscompostos

Lima, I. V. (2003). Ferro. Gerenciamento de toxicidade. São Paulo: Atheneu.

Moreno, J. (1996). Avaliação Sanitária das captações e reservatórios de águas em pequenas comunidades rurais da região de Bauru - SP. (Dissertação (Mestrado) - Escola de Engenharia de São Carlos, Universidade de São Paulo).

Prianti, J.N.G.; Carmo, F.H., Mendes, C.G.N.,Lacava, P.M. (2003). Redução de ferro e manganês na água: solução para o consumidor. Revista Meio Filtrante.1(3),8-9. https://silo.tips/download/remoao-e-controle-de-ferro-e-manganes-em-aguas-para-consumo-humano\#

Scheneider, R. P., Tsutiya, M. T., (2001). Membranas filtrantes para o tratamento de água, esgoto e água de reuso. São Paulo: Associação Brasileira de Engenharia Sanitária e Ambiental.

Simão, G., Damiani, A. P. M., Alexandre, N. Z. \& Silva, B. G. (2020). Qualidade da água utilizada para consumo humano em áreas rurais, estudo de caso no município de Santa Rosa do Sul-Santa Catarina. Holos Environment, 20(1). https://www.cea-unesp.org.br/holos/article/view/12368.

Sodré. F. F. (2005). Especiação de cobre em águas naturais: influência de fatores associados à urbanização. Tese (Doutorado). Universidade Federal do Paraná - Programa de Pós graduação em Química. Setor de Ciências Exatas. Curitiba.

Taffarel, S. R. \& Rubio, J. (2009). On the removal of Mn2+ ions by adsorption onto natural and activated Chilean zeolites.Minerals Engineering, 22(4), 336-343.

Tekerlekopoulou, A. G.; Vasiliadou, I. A. \& Vayenas, D. V. (2008). Biological manganese removal from potable water using trickling filters. Biochemical Engineering Journal, 38(3), 292-301.

Vagliasindi, F. G. A; Roccaro, P.; Barone, C. \& Mancini, G. (2007). Removal of manganese from water supplies intended for human consumption: a case study. Desalination, 210(1-3), 205-214.

Victorino, C. J. A. (2007). Planeta água morrendo de sede: uma visão analítica na metodologia do uso e abuso dos recursos hídricos. Porto Alegre:Edipucrs Vijayaraghavan, K.; Yun \& Yeoung, S.(2008). Bacterial biosorbents and biosorption. Biotechnology Advances, 26(3), $266-291$.

VISTUBA, J. P.(2010) Remoção de ferro e manganês de água de abastecimento por meio de filtração adsortiva. Dissertação (Mestrado) - Universidade Federal de Santa Catarina

Zambetta, P. M.A. (2006). Espécies químicas inorgânicas (Al, As, $\mathrm{Cd}, \mathrm{Cr}, \mathrm{Cu}, \mathrm{Fe}, \mathrm{Hg}, \mathrm{Mn}, \mathrm{Ni}, \mathrm{Pb}$ e $\mathrm{Sn}$ ) no sedimento e nos sólidos em suspensão do rio Corumbataí, SP. 73 f. Dissertação (Mestrado). Universidade de São Paulo - Escola Superior de Agricultura "Luiz de Queiroz". Piracicaba. 